Stanislaw Kozak

Andreas R. Gantenbein

Hansruedi Isler

Kathleen R. Merikangas

Jules Angst

Alex Gamma

Reto Agosti

\section{Nosology and treatment of primary headache in a Swiss headache clinic}

Received: 18 January 2005

Accepted in revised form: 15 March 2005

Published online: 13 May 2005

*S. Kozak •*A.R. Gantenbein $(\bowtie) \cdot$ H. Isler Headache and Pain Unit,

Neurology Department,

Zürich University Hospital,

Frauenklinikstrasse 26,

8091 Zürich, Switzerland

e-mail: andy.gantenbein@gmx.ch

Tel.: +41-1-255-5514

Fax: +41-1-255-4507

K.R. Merikangas

National Institute of Mental Health,

$\mathrm{NIH}$, Bethesda, MD, USA

J. Angst • A. Gamma

Zurich University Psychiatric Hospital,

Zurich, Switzerland

\section{R. Agosti}

Headache Unit,

Hirslanden Clinic, Zurich, Switzerland

*Both authors contributed equally to this work.

\begin{abstract}
We assessed demographics, diagnoses, course, severity, impact and treatment of primary headache outpatients from records in the Headache and Pain Clinic, Neurological Department, Zürich University Hospital. All outpatients seen from 1996 to 1998 for migraine, tension-type headache, and both, were included.

Diagnoses, drug, physical and alternative treatments before and after referral were listed. Descriptive statistics were used for differences between the general population and this sample, the diagnoses, and treatments. The coexistence of migraine and tension-type headache, and the high frequencies of headache days would have excluded most migraine patients from typical drug trials: at best, only one third were eligible. The socioeconomic impact of combined
\end{abstract}

and difficult syndromes calls for comprehensive management beyond simple treatment with instant relief drugs. The diagnostic and therapeutic practices of referring physicians exposed a deficit of information on headache, and a need for relevant education.
Key words Primary headache • Tertiary care $\cdot$ Demographics • Epidemiology $\bullet$ Drug treatment

\section{Introduction}

Headaches without adequate structural damage, predominantly tension headache and migraine, are a major cause of loss of productivity [1] and health expenditure. The medical sciences of our times (and of the last 300 years) have so far not found a plausible way to account for these disorders of otherwise healthy persons of all ages, constitutions and social situations. Headache problems have been relegated among the so-called civilisation diseases, which means that deficient habits and faulty ways of life, and ultimately, sin would be responsible, but history [2] shows that problematic headache was at least as important in ancient societies as it is today, and geographic differences are too vague to interpret because of widely diver- 
gent local conditions and methods. Headache has been a normal feature of the general human condition (conditio humana), since its lifetime prevalence is above $95 \%$ of the total population, but problematic headache which afflicts at least $10 \%$ is a disease, and needs to be treated, urgently, and with adequate know-how.

The Headache and Pain Clinic (HPC) in the Neurology Department, Zurich University Hospital, is a service for the assessment and management of difficult headache problems. Since its beginning in 1966, patients have been referred by various specialist physicians and surgeons in various hospitals and in private practice, as well as general practitioners. Self-referrals, usually upon recommendation by follow-up patients, have also been accepted. These patients had usually been treated unsuccessfully by several physicians and laymen. They required time-consuming, individualised care. Therefore, systematic review of data had to be limited to small samples of the clinic population [3, 4]. Meanwhile Merikangas and co-workers found surprising data on headache and migraine in their Zurich cohort study [1], where they followed a sample of the general population over 20 years. Migraine and tension-type headache were shown to be major problems in the Zurich population at large. The need for corresponding larger studies of the headache clinic population became obvious. In order to assess the characteristics of the population and as a preparation for appropriate prospective studies, we investigated retrospectively a sample of 1625 patients of our clinic.

\section{Patients and methods}

From the files of the clinic we selected those patients with migraine, tension-type headache and combinations of migraine and tension-type headache who had been seen in the years 1996-1998 $(n=1625)$. The following data were collected in a questionnaire designed for this purpose.

Sex, age and native language; marital status; children; educational status; occupation; referral; diagnosis before and after referral; age of onset of headache; frequency of headache (headache days per month); loss of working days per month and per year; other diseases, and drugs taken for them; special investigations: CT scan, MRI and EEG before and after referral; longterm prophylactic drugs for headache before and after referral; drugs for acute headache (attacks) before and after referral; drugs discontinued because of adverse effects, or lack of effect; alternative, or complementary treatment before and after referral; special remarks.

Where necessary, missing data were obtained by telephone interview using the same form. However it was not possible to reach every patient for this purpose. The following data have not been obtained: onset of headache in $17.9 \%$, education and profession in less than 5\%; absence from school/work in less than
$2 \%$; frequency of headaches and marital state in $1 \%$. Missing data was excluded for the analysis.

Data were analysed using SPSS (version 8.0) and SAS 8.2 for Windows. $\chi^{2}$ - and $U$-tests were used to assess the statistical significance of differences between headache subtypes.

\section{Results}

Demography and clinical characteristics

According to the IHS criteria [5], $47.3 \%$ of the patients had migraines, $20 \%$ had tension-type headaches and $32.7 \%$ had migraines combined with tension-type headaches. The distribution of demographic characteristics in this clinical sample $(n=1625)$ was typical of treatment samples: women were over-represented by $72 \%$ as against $28 \%$ men, nearly $3: 1$, the proportion usually found in migraine. See also Table 1.

The age range of the migraine patients was 8-74 years, with a mean age of 39.3 years. Tension-type headache patients were between 7 and 82 years, with a mean age 37.4. The mean age of onset was 20.5 years for migraine and 30.2 years for tension-type headache (Fig. 1).

On average, migraine patients had a lower frequency of headache days per month than tension-type headache patients. There were more patients with less than 4 headache days per month in migraine $(28 \%$ as against $5 \%$ in tensiontype headache) and more patients with daily headache in tension-type headache (61\% as against $9.3 \%$ in migraine). A large majority of tension-type headache patients had daily headache $(61 \%)$. Altogether $82.4 \%$ fulfilled the criteria of chronic tension-type headache. This clearly outweighs the incidence of chronic tension-type headache found in the general population of Germany and Denmark $(3 \%)[6,7]$.

Nearly one third of all migraine patients fulfilled the criteria for chronic migraine, whereas in the general German population only $2 \%$ of the migraine sufferers had 15 or more headache days per month [8]. See also Table 2.

\section{Impact}

$57.8 \%$ of 748 patients with migraine, and $83.4 \%$ of 314 patients with tension-type headache had no loss of school or work days. $28.8 \%$ of the migraine patients, and $9 \%$ of the patients with tension-type headache had lost up to 30 days per year. $13.4 \%$ of the migraine patients, and $7.6 \%$ of the tension-type headache patients reported work loss of more than one month per year. Some had not been able to work at all. 
Table 1 Demographics. Numbers in parentheses are values expected in the population of Switzerland

\begin{tabular}{|c|c|c|c|c|}
\hline & Women & Men & Total & $p_{\mathrm{FM}}{ }^{\mathrm{a}}$ \\
\hline Patients, $n$ & 1166 & 459 & 1625 & \\
\hline Patients, $\%$ & $71.8(51.2)$ & $28.2(48.8)$ & 100 & \\
\hline \multicolumn{5}{|l|}{ Age distribution (years) } \\
\hline Median age & 38 & 37 & 38.5 & 0.16 \\
\hline $4-19, \%$ & 6.5 & 7.8 & 6.9 & \\
\hline $20-39, \%$ & 47.0 & 51.0 & 48.1 & \\
\hline $40-64, \%$ & 43.1 & 37.0 & 41.4 & \\
\hline $65-79, \%$ & 3.2 & 3.5 & 3.6 & \\
\hline $80-86, \%$ & 0.2 & 0.7 & 0.4 & \\
\hline Marital status & & & & 0.005 \\
\hline Single, $\%$ & 31.8 & 40.1 & $34.1(42.0)$ & \\
\hline Married, $\%$ & 54.3 & 51.1 & $55.3(46.6)$ & \\
\hline Divorced, \% & 9.6 & 6.4 & $8.7(5.5)$ & \\
\hline Widowed, \% & 2.3 & 0.9 & $1.9(5.9)$ & \\
\hline Education (25-64 years) & & & & 0.001 \\
\hline Basic education, $\%$ & $24.7(25.7)$ & $12.8(12.9)$ & $21.3(19.3)$ & \\
\hline Trade school, $\%$ & $68.1(61.5)$ & $71.0(54.0)$ & $68.9(57.8)$ & \\
\hline Tertiary education, $\%$ & $7.2(12.8)$ & $16.2(33.1)$ & $9.8(22.9)$ & \\
\hline Foreign language speakers & 34.1 & 39.4 & $34.6(19)$ & 0.05 \\
\hline
\end{tabular}

${ }^{\mathrm{a}} U$-tests and $\chi^{2}$-tests, respectively, comparing females $v s$. males

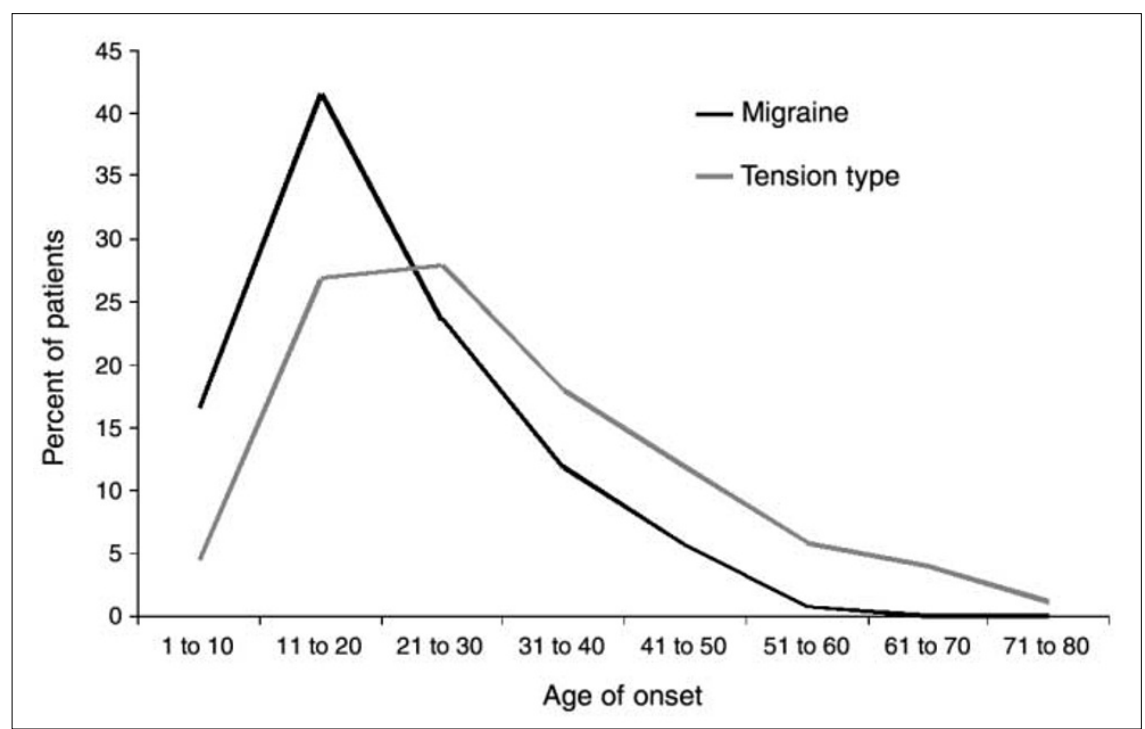

Fig. 1 The age of onset-curve has a sharp peak at 13 years in the migraine group (puberty, prepuberty)
Diagnosis and special investigations

Major differences were encountered in diagnoses and treatment before and after assessment in the headache clinic.

The diagnoses of migraine and that of tension-type headache were established much more often in the clinic than by referring physicians. Of headaches finally diagnosed as migraine, $57 \%$ were referred as migraine, $6 \%$ as tension-type headache with or without migraine and $37 \%$ as headache without further specification. The situation was even more incongruous in tension-type headache where $79 \%$ were referred as unspecified headache, $17 \%$ as tension-type headache with or without migraine and $4 \%$ as migraine (Fig. 2).

The most frequent special investigations were: CT scan $(18.2 \%$ before, $7.6 \%$ after first consultation), EEG (10\% before, $2.3 \%$ after first consultation) and MRI (5.5\% before, $3.8 \%$ after first consultation). No pathology was found which would have led to further investigations, interventions or change of treatment. 
Table 2 Characteristics of headache types. Numbers are percentages or medians (with quartiles in parentheses)

\begin{tabular}{|c|c|c|c|c|c|c|c|c|c|}
\hline & \multicolumn{3}{|c|}{ Migraine } & \multicolumn{3}{|c|}{ Tension } & \multicolumn{3}{|c|}{ Both } \\
\hline & $\mathrm{F}$ & M & $p_{\mathrm{FM}^{\mathrm{a}}}$ & $\mathrm{F}$ & M & $p_{\mathrm{FM}^{\mathrm{a}}}$ & $\mathrm{F}$ & $\mathrm{M}$ & $p_{\mathrm{MT}^{\mathrm{a}}}$ \\
\hline Patients, $n$ & 597 & 170 & - & 169 & 157 & - & 400 & 132 & - \\
\hline Patients, $\%$ & 36.7 & 10.5 & - & 10.4 & 9.7 & - & 24.6 & 8.1 & - \\
\hline Age & $39(30-49)$ & $39(31-47)$ & 0.64 & $35(24-50)$ & $34(26-47)$ & 1.0 & $36(26-49)$ & $36(27-45)$ & 0.002 \\
\hline Age of onset & $19(13-27)$ & $16(10-29)$ & 0.05 & $27(19-42)$ & $26(20-37)$ & 0.82 & $17(12-26)$ & $20(13-30)$ & 0.001 \\
\hline \multicolumn{10}{|l|}{ Frequency } \\
\hline $\begin{array}{l}\text { headache } \\
\text { days/month }\end{array}$ & $8(4-14)$ & $6(4-12.5)$ & 0.04 & $30(17.5-30)$ & $30(16-30)$ & 0.6 & $18(9-30)$ & $17.5(8-30)$ & 0.001 \\
\hline $\begin{array}{l}<4 \text { headache } \\
\text { days/month, \% }\end{array}$ & 18.8 & 25.3 & 0.06 & 3.0 & 7.6 & 0.06 & 6.3 & 6.1 & 0.001 \\
\hline Daily headache, \% & 8.2 & 12.4 & 0.10 & 60.4 & 58.0 & 0.66 & 35.3 & 37.9 & 0.001 \\
\hline $\begin{array}{l}\text { No. school/work } \\
\text { days lost }{ }^{\mathrm{b}}\end{array}$ & $18(12-48)$ & $13.5(6-30)$ & 0.20 & $41(12-144)$ & $24(10-48)$ & 0.29 & $18(12-42)$ & $18(12-57)$ & 0.001 \\
\hline
\end{tabular}

${ }^{a} U$-tests. $p_{\mathrm{FM}}$ compares females $v s$. males; $p_{\mathrm{MT}}$ compares migraine $v s$. tension headache subjects

bOnly subjects who have had any absences are considered

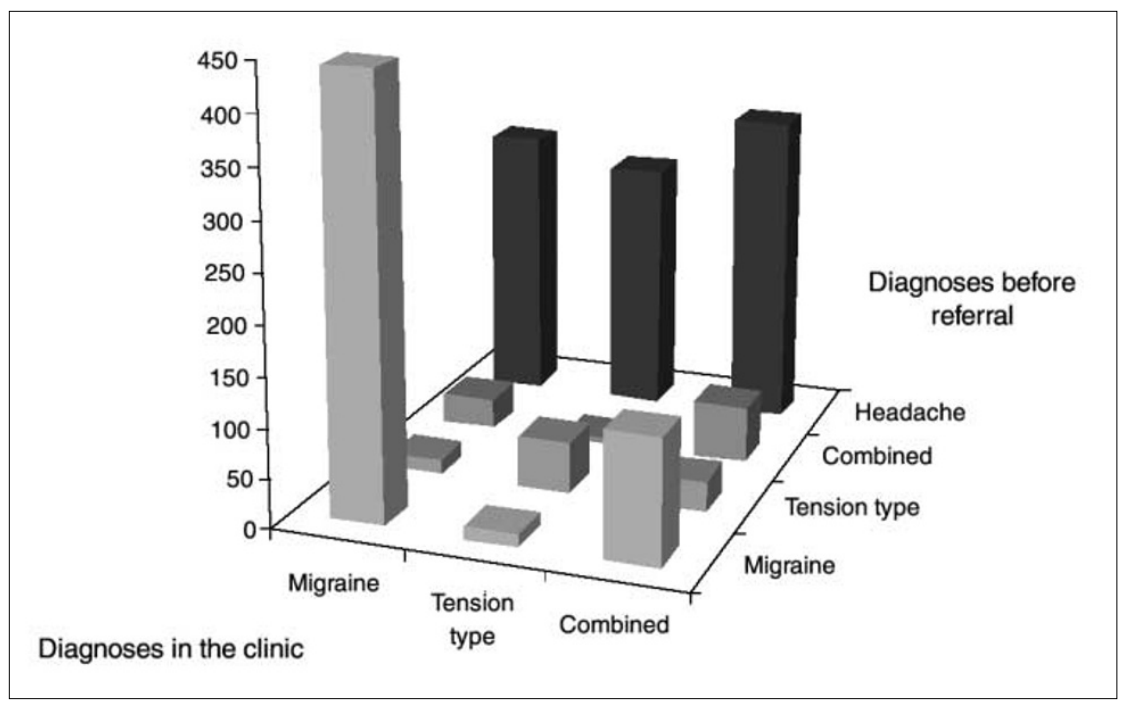

Fig. 2 More than one half of the migraine group were referred as migraine but only one sixth of the tension-type headaches, and one tenth of the combined headaches came in with a correct diagnosis. Most of the headaches were referred as "unspecific headache"
Treatment before and after first consultation in the HPC

See Table 3. Monotherapy was the exception both before referral and in HPC prescriptions (altogether 64). The main difference between treatment by referring doctors and treatment in the HPC was a shift from instant relief drugs to prophylactics, especially to magnesium (new: 1062), antidepressants (691) and beta-blockers (461). There was a modest decrease of ergotamines, matched by a comparable increase of triptans. However most patients kept the instant relief drugs they were using, usually declaring that they helped them best of all, independent of their pharmaceutical nature.
Previous alternative or complementary treatment (acupuncture, aromatherapy, Atlaslogy, Bach flowers, bioresonance, china oil, chiropractic, colour therapy, craniosacral therapy, electrotherapy, foot reflex massage, homeopathy, laser treatment, lymph drainage, magnetopathy, morphology, neural therapy, neurolinguistics, osteopathy, phytotherapy, psychophony, Reiki, Shiatsu, vitalogy, yoga) was reported by 484 patients while 1141 did not report such treatments.

The most frequently reported complementary treatments were acupuncture (338) and homeopathy (120), while all other methods were reported by small minorities. 
Table 3 Drug treatment before and after initial consultation at HPC (number of drugs taken by the 1625 patients, often more than one by each patient)

\begin{tabular}{|c|c|c|c|}
\hline & Previous (stopped) & Continued at HPC & HPC prescribed (new) \\
\hline \multicolumn{4}{|l|}{ Acute type } \\
\hline Benzodiazepines & 12 & 3 & 2 \\
\hline Ergotamines & 456 & 402 & 141 \\
\hline Opioids & 45 & 19 & 8 \\
\hline Simple analgesics & 784 & 1234 & 417 \\
\hline Combined analgesics & 186 & 202 & 24 \\
\hline Triptans & 114 & 139 & 224 \\
\hline \multicolumn{4}{|l|}{ Prophylactic type } \\
\hline Anticonvulsants & 26 & 3 & 30 \\
\hline Antidepressants* & 193 & 104 & 691 \\
\hline Benzodiazepines & 28 & 3 & 3 \\
\hline Beta blockers & 239 & 67 & 461 \\
\hline Calcium antagonists & 360 & 22 & 325 \\
\hline Ergotamines & 295 & 16 & 49 \\
\hline Magnesium & 29 & 85 & 1062 \\
\hline Serotonin antagonists** & 16 & 3 & 11 \\
\hline
\end{tabular}

*Tricyclics and serotonin reuptake inhibitors (SSRIs)

**Methysergide and pizotifen

\section{Discussion}

Demography and clinical characteristics

Compared to the general population of Switzerland in 1998 [9] there was a preponderance of the age group from 20 to 65 years (89\% against $61.6 \%$ ). Severe headache problems appear to prevail in the middle age groups where workload, family stresses and competition are more likely to become unbearable. The marital status of the patients presented no important differences to the distribution in the general population.

The educational characteristics showed no over-representation of higher learning, contrary to the popular prejudice about migraine as a disease of intellectuals. The percentage of patients with tertiary education was only half of that found in the general population [9]. As more than one third of all patients were native speakers of other languages than the official German of the region of Zürich, this permits us to infer that those with a socially underprivileged status may be over-represented in this sample.

Although the onset of migraine in our sample was 10 years lower than the onset of tension-type headache, the patients in the migraine group were on average 2 years older than the tension-type headache patients. This could imply a longer duration of the migraine disease.

There were abundant differences in the frequency of headache of our population compared to epidemiological data from Germany and Denmark. Chronic tension-type headache was over-represented nearly 24 times, and chronic daily headache combined with migraine, though non-existent in the published German data, was found in nearly $10 \%$ of the migraine patients, while $29.6 \%$ had 15 or more headache days per month. This could well be explained with very frequent headaches as a motive for seeking professional help.

We applied the selection criteria from the revised IHS guidelines for controlled trials of drugs in migraine [10]. A maximum of 390 of $1299(30 \%)$ patients with migraine or migraine and tension-type headache would be eligible for trials with acute or prophylactic drugs, due to the high migraine frequency. Further need for medical treatment may be greatest where the selection criteria of the IHS guidelines for migraine drug trials [10] will be least applicable.

Impact

Only one third of the whole group reported loss of work or school days. As there were altogether 1166 women, more than half of them without gainful occupation, and more or less able to wait at home for the end of a bad headache attack or a bad headache episode, the present reports are showing only part of this problem. Merikangas and co-workers [1] found up to $90 \%$ impairment of social and leisure activities, and up to $75 \%$ occupational impairment in the migraine sufferers among the high-risk group of the Zurich cohort study. 
According to the IHS criteria [5] and definitions the intensity of tension-type headache should not be severe, that is, not severe enough to block the usual daily activities. Contrary to these expectations $16.6 \%$ of our tensiontype headache patients reported loss of work days, as against $42.2 \%$ of the migraine patients, which is more in keeping with the migraine criteria defining attacks of moderate to severe headache. In a sizeable minority, disability occurred on more than 30 days per year: $11.3 \%$ of all patients, $13.4 \%$ of those with migraine and $7.6 \%$ of those with tension-type headache. These severe problems may be concentrated in the specialist clinic but they are closely related to the encroachment on the quality of life in the general population [1].

\section{Treatment}

Treatment before and after HPC prescriptions was usually drug treatment, predominantly using more than one drug, combining at least one prophylactic and one instant relief type drug. Previous treatment consisted mostly of instant relief drugs, whereas the HPC preferred prophylactic drugs for treatment. The salient feature was the change from 29 patients taking magnesium previously to 1062 who had it prescribed at HPC ( 85 continuing from before). Similar but lower increases were observed in antidepressants (193 to 691, 104 continuing) and beta-blockers (239 to 461,67 continuing). The increase in beta-blockers was associated with a shift from propranolol to nadolol. In 315 cases flunarizine was stopped and cyclandelat was newly prescribed in 260 patients. Both these changes were intended for better tolerability.

Among the instant relief drugs, simple analgesics showed both the highest number of users and the highest continuity of use, with similar patterns but lower numbers for ergotamine compounds and triptans. Opioids and benzodiazepines were only used by marginal minorities. One third reported various complementary or alternative treatments.

\section{Conclusions}

The typical patient at the Headache and Pain Clinic is a 35-year-old married woman with both migraine without aura and tension-type headache with a frequency of 15 headache days per month, resulting from both syndromes.

Age distribution of migraine and tension headache patients appears to be different and typical for each syndrome. The findings are more compatible with a continuous spectrum of primary headache syndromes than with the concept of neatly separate nosological entities, which is in turn hardly compatible with clinical experience where replacement or transformation of tension-type headache by or into migraine, and vice versa, is reported by a very important minority of patients.

The most striking difference was found between diagnoses by referring physicians and diagnoses established in the clinic. Over $80 \%$ of tension-type headaches, and over one third of migraines diagnosed in the clinic had been referred with unspecified headache diagnoses.

Patients referred to the headache clinic reported medication closely resembling that of the epidemiological studies of Isler et al. [11] in the region of most frequent referral, the Canton of Zürich and its surroundings. This consisted mainly of analgesics for acute attacks, sometimes overused. Prophylactics were applied rarely and rather indiscriminately, often without consideration of their specific indication for migraine.

As a whole, our study indicated that availability of information on current diagnosis and treatment, as it were, is still insufficient in referring general practitioners.

\section{References}

1. Merikangas KR, Whitaker AE, Isler H, Angst J (1994) The Zurich Study: XXIII. Epidemiology of headache syndromes in the Zurich cohort study of young adults. Eur Arch Psychiatry Clin Neurosci 244:145-152

2. Isler H, Clifford Rose F (2000) The history of headache. In: Olesen J, Tfelt-Hansen P, Welch KMA (eds) The headaches, 2nd edn. Lippincott Williams \& Wilkins, Philadelphia, pp 1-9
3. Isler H (1983) Das Zeitmuster als Leitsymptom der Migräne. In: Seitz D, Vogel P (eds) Hämoblastosen, zentrale Motorik, iatrogene Schäden, Myositiden. Springer, Berlin, pp 986-989

4. Isler H (1986) Frequency and time course of premonitory phenomena. In: Amery W, Wauquier A (eds) The prelude to the migraine attack. Bailliere Tindall, London, pp 44-53
5. Headache Classification Committee of the International Headache Society (1988) Classification and diagnostic criteria for headache disorders, cranial neuralgia, and facial pain. Cephalalgia 8[Suppl 7]:1-96

6. Rasmussen BK, Jensen R, Schroll M, Olesen J (1991) Epidemiology of headache in a general population - a prevalence study. J Clin Epidemiol 44:1147-1157 
7. Göbel H (1997) Kopfschmerz vom Spannungstyp. In: Göbel H (ed.) Die Kopfschmerzen. Springer, Berlin, p 374

8. Göbel H (1997) Epidemiologie von Kopfschmerzen. In: Göbel H (ed) Die Kopfschmerzen. Springer, Berlin, $p$ 118
9. Bundesamt für Statistik (2000)

Bevölkerung: Zivilstand, Heiraten und Scheidungen [WWW document]. URL http://www.statistik.admin.ch/stat_ch/b er01/dufr01.htm
10. Tfelt-Hansen P, Block G, Dahlöf C, Diener H-C, Ferrari MD, Goadsby PJ et al (2000) Guidelines for controlled trials of drugs in migraine, 2nd edn. Cephalalgia 20:765-786

11. Isler H, Merikangas KR, Angst J (1991) Treatment patterns of migraine in the community. Cephalalgia [Suppl 11]:110 